\title{
Working with animals is 'in her blood'
}

\author{
Santina Caruso, BS, LVT, RLATg, Senior Veterinary Associate, \\ Merck Research Laboratories, Boston, MA.
}

Ms. Caruso talks about her lifelong passion for animal care and shares her long-term career goals.

\begin{abstract}
When did you first become interested in the field of veterinary technology? From the age of 5, I could be found in the woods, the fields or the frog pond looking for sick or injured animals that needed help. At the age of 9, I would ride my bicycle to the local veterinarian with the animals I found, knowing he would always squeeze me in. He would let me assist with the injured animals, encouraging me to think about what may have happened to them. He used to tell me that I had a gift with animals. At the age of 10, I knew that when I grew up I was going to 'fix' animals. At the age of 12 , I volunteered my summer to working on a farm but found that I would rather be learning about snakes, birds and frogs. At the age of 13, I had the opportunity to work with a veterinarian, and I began working at a local kennel at the age of 16 .
\end{abstract}

\section{You served in the United States Navy} for 12 years, where you were trained in Dental Hygiene at the National Naval Medical Center (Bethesda, MD), before deciding to pursue a career as a veterinary technician. How did this experience lead to a career caring for animals?

It was a constant reminder that I was in the wrong field: the more I worked with humans, the more I wanted to be working with animals. The day a veterinarian army officer sat in my dental chair and began conversing about the dogs he had worked with was the day that I knew I had to make strides toward a similar career. As soon as I received a letter of acceptance into the officer's program, I enrolled at Old Dominion University as a pre-vet student. Life has a way of throwing curve balls, though; I never finished that program because I had an accident that ultimately resulted in a medical retirement from the Navy. The accident turned out to be a blessing in disguise when my father became stricken with cancer because I would have never been able to care for him while serving in the Navy.

Based on your experiences, what advice would you give to someone thinking of switching to a career in laboratory animal science?

It needs to be 'in your blood'. One cannot switch to a career in laboratory animal science for the money or benefits, nor can one work in laboratory animal science without believing that it takes lives to save lives. One should understand that working in an animal research facility involves providing humane and responsible care while working to reach scientific goals. In the words of W.M.S. Russell and R.L. Burch, "[ $t$ ] he humanist possible treatment of experimental animals, far from being an obstacle, is actually a prerequisite for successful animal experiments.”

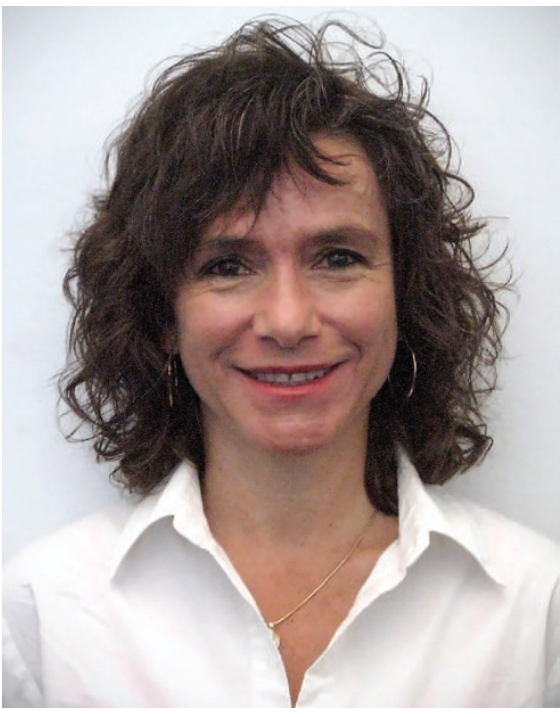

What are your future or long-term career goals?

My immediate goal is to obtain a Surgical Research Anesthetist (SRA) Certification from the Academy of Surgical Research, which requires a record of 30 case logs. Once this certification is completed, I will work toward obtaining Surgical Research Technician (SRT) Certification and then eventually Surgical Research Specialist (SRS) Certification. My long-term goal is to take the surgical experience I've gained along with the qualifications I've earned and expand our current surgical services to the labs, allowing more time for them to concentrate on the science.

Is there anything else you would like to share with Lab Animal readers?

Remember to thank the animal care and health technicians daily. They are the eyes and ears of laboratory animal science and the link between humane care and scientific goals. 